\title{
Cost-effectiveness of three strategies for second-line erlotinib initiation in nonsmall- cell lung cancer: the ERMETIC study part 3
}

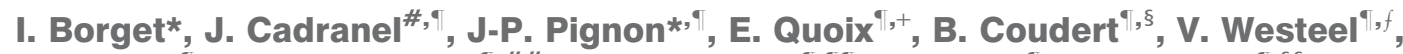

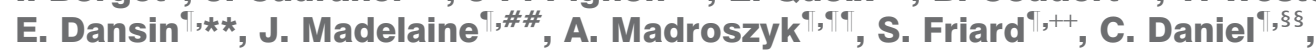 \\ F. Morin ", C. Chouaid ${ }^{\pi, f f}$ and the ERMETIC*** Collaborative Group
}

ABSTRACT: Several clinical and biological parameters are known to influence the efficacy of second-line erlotinib therapy for nonsmall cell lung cancer (NSCLC), but their medico-economic impact has not been evaluated. The objective of this study was to compare the incremental costeffectiveness ratios of strategies for second-line erlotinib initiation in NSCLC: clinically guided initiation (nonsmoking females with adenocarcinoma received erlotinib; all other patients received docetaxel) and biologically guided selection (patients with epidermal growth factor receptor (EGFR) mutation received erlotinib; patients with wild-type EGFR or unknown status received docetaxel), compared with initiation with no patient selection (strategy reference).

A Markov model was constructed. Outcomes (overall and progression-free survival), transition probabilities and direct medical costs (from the French third-party payer's perspective) were prospectively collected for individual patients treated with either erlotinib or docetaxel, from treatment initiation to disease progression. Published data were used to estimate utilities and post-progression costs. Sensitivity analyses were performed.

The biologically and clinically guided strategies were both more efficient (incremental qualityadjusted life-yrs equal to 0.080 and 0.081 , respectively) and less expensive (cost decrease equal to $€ 5,020$ and $€ 5,815$, respectively) than the no-selection strategy, and the biologically guided strategy was slightly less expensive than the clinically guided strategy. Sensitivity analyses confirmed the robustness of the results.

The cost-effectiveness of second-line NSCLC treatment is improved when patients are selected on either clinical or biological grounds.

KEYWORDS: Cost-utility, EGFR mutation, erlotinib, nonsmall cell lung cancer

ung cancer is the leading cause of cancerrelated death and represents a considerable public health burden worldwide. Estimates from the USA indicate that per-patient lung cancer management costs rose by a factor of at least five between 1991 and 2002 [1, 2]. These costs may increase further still with the introduction of novel targeted therapies. Nonsmall cell lung cancer (NSCLC) accounts for $85 \%$ of all primary lung cancers. First- and second-line chemotherapy is the standard of care for patients who have advanced NSCLC with good performance status, improving symptom control and survival compared with the best supportive care [3-5]. When disease progression occurs after initial treatment, second-line options include two chemotherapeutic agents (docetaxel and pemetrexed) and erlotinib, an epidermal growth factor receptor (EGFR) tyrosine kinase inhibitor [6]. Docetaxel improves overall survival (OS) relative to the best supportive care [5]. Pemetrexed showed similar efficacy but less toxicity when compared head-to-head with docetaxel in a phase III randomised trial involving previously treated patients with advanced NSCLC [4]. In a landmark trial, erlotinib improved OS and quality of life when compared with the best supportive care, with a median OS benefit of 2 months relative to the placebo arm [6]. The rates of response to erlotinib were higher in some patient subgroups, including patients of Asian origin, females, neversmokers and patients with adenocarcinoma [6-8]. However, never-smoker status was the only clinical factor associated with improved OS in multivariable analysis. The influence of clinical factors on outcomes was recently evaluated in a retrospective study of 121 consecutive Caucasian patients treated

\section{AFFILIATIONS}

*Institut Gustave Roussy, Villejuif, ${ }^{\#}$ AP-HP Hôpital Tenon and University Pierre et Marie Curie (UPMC) University Paris 06, ${ }^{f f}$ AP-HP Hôpital St-Antoine and UPMC University Paris 06,

${ }^{++}$Hôpital Foch,

${ }^{\S \S}$ Institut Curie,

-Intergroupe Francophone de Cancérologie Thoracique (IFCT), Paris,

+Hôpitaux Universitaires de Strasbourg, Strasbourg, ${ }^{\S} \mathrm{CLCC}$ - CHU, Dijon, ${ }^{f} \mathrm{CHU}$ Besançon, Besançon,

${ }^{* \star} \mathrm{CLCC}-\mathrm{CHU}$, Lille,

\#\#CHU - CLCC, Caen,

"CLCC Paoli Calmette, Marseille, France.

***For a list of the ERMETIC Collaborative Group members see the Acknowledgements section.

CORRESPONDENCE

I. Borget

Etudes et Recherche en Économie de la Santé

Institut Gustave Roussy 39 rue Camille Desmoulins 94805 Villejuif Cedex France E-mail: isabelle.borget@igr.fr

Received:

Dec 302010

Accepted after revision: May 172011

First published online: June 092011

European Respiratory Journal Print ISSN 0903-1936 Online ISSN 1399-3003 
with erlotinib in a routine clinical setting. Patients with adenocarcinoma had better progression-free survival (PFS) than other patients, but similar OS. Likewise, never-smokers had longer PFS (7 months) and OS (13 months) than smokers and ex-smokers. Sex had no noteworthy influence [7, 9]. Molecular predictors of erlotinib efficacy were also evaluated when sufficient tumour tissue was available [10-13]. Preliminary studies suggested that strong EGFR protein expression, measured with immunohistochemical methods and high EGFR gene copy number, were associated with better response and survival rates on erlotinib [14]. However, these analyses were retrospective and limited by sample availability. It has since been established that EGFR mutation status influences the efficacy of EGFR tyrosine kinase inhibitors in both first- and second-line settings [15-18].

In 2005, the French National Cancer Institute (INCa) funded a nationwide 2-yr multicentre prospective study to address the standardisation of mutation analysis. The study, entitled "Evaluation of EGFR mutation status for EGFR-[tyrosine kinase inhibitor]TKI administration in nonsmall-cell lung carcinoma (ERMETIC)"', involved 16 French clinical centres, and pathology and medical laboratories. The project had three successive objectives: 1) to validate routine sequencing-based screening for EGFR and KRAS mutations on fixed paraffin-embedded tissues [19]; 2) to select and rank clinical, pathological and biological predictors of the response to EGFR-TKIs and the resulting clinical benefit in a large prospective patient cohort [8]; and 3) to determine the most cost-effective strategy for prescribing EGFRTKIs, with or without the use of EGFR biomarkers. The present study focuses on part 3 of the ERMETIC project.

There are currently no published clinical trials directly comparing EGFR mutation screening with no screening prior to secondline erlotinib initiation for NSCLC. We conducted an indirect comparison of the cost-utility of EGFR mutation screening, based on data from two prospective studies, namely the ERMETIC prospective multicentre cohort [8] and a prospective, randomised multicentre trial (the GFPC0506 study) comparing docetaxel and pemetrexed in the second-line setting [20]. The objective was to compare, using a Markov model, the costeffectiveness ratios (CERs) of three hypothetical strategies for second-line erlotinib initiation for NSCLC: initiation with no patient selection, clinically guided initiation (nonsmoker females with adenocarcinoma receiving erlotinib; other patients receiving docetaxel) and initiation based on EGFR mutation status (erlotinib for EGFR-mutated patients and docetaxel for all other patients).

\section{PATIENTS AND METHODS \\ Study population}

The study population consisted of patients with advanced NSCLC in whom at least one platinum-based chemotherapy regimen had failed and who were eligible for erlotinib or chemotherapy.

\section{Strategies compared}

The three hypothetical strategies for second-line erlotinib initiation are shown in figure 1. In the no-selection strategy, all patients were assumed to receive erlotinib. In the clinically guided strategy, patients with favourable clinical features (female neversmokers with adenocarcinoma) were assumed to receive erlotinib, while all other patients were assumed to receive docetaxel. In the biologically guided strategy, patients with known EGFR mutations were assumed to receive erlotinib, while patients with no EGFR mutations or unknown status were assumed to receive docetaxel. Docetaxel was chosen as the alternative to erlotinib as it is routinely used for second-line NSCLC therapy [3] and is more cost-effective than pemetrexed [20, 21]. It was assumed that

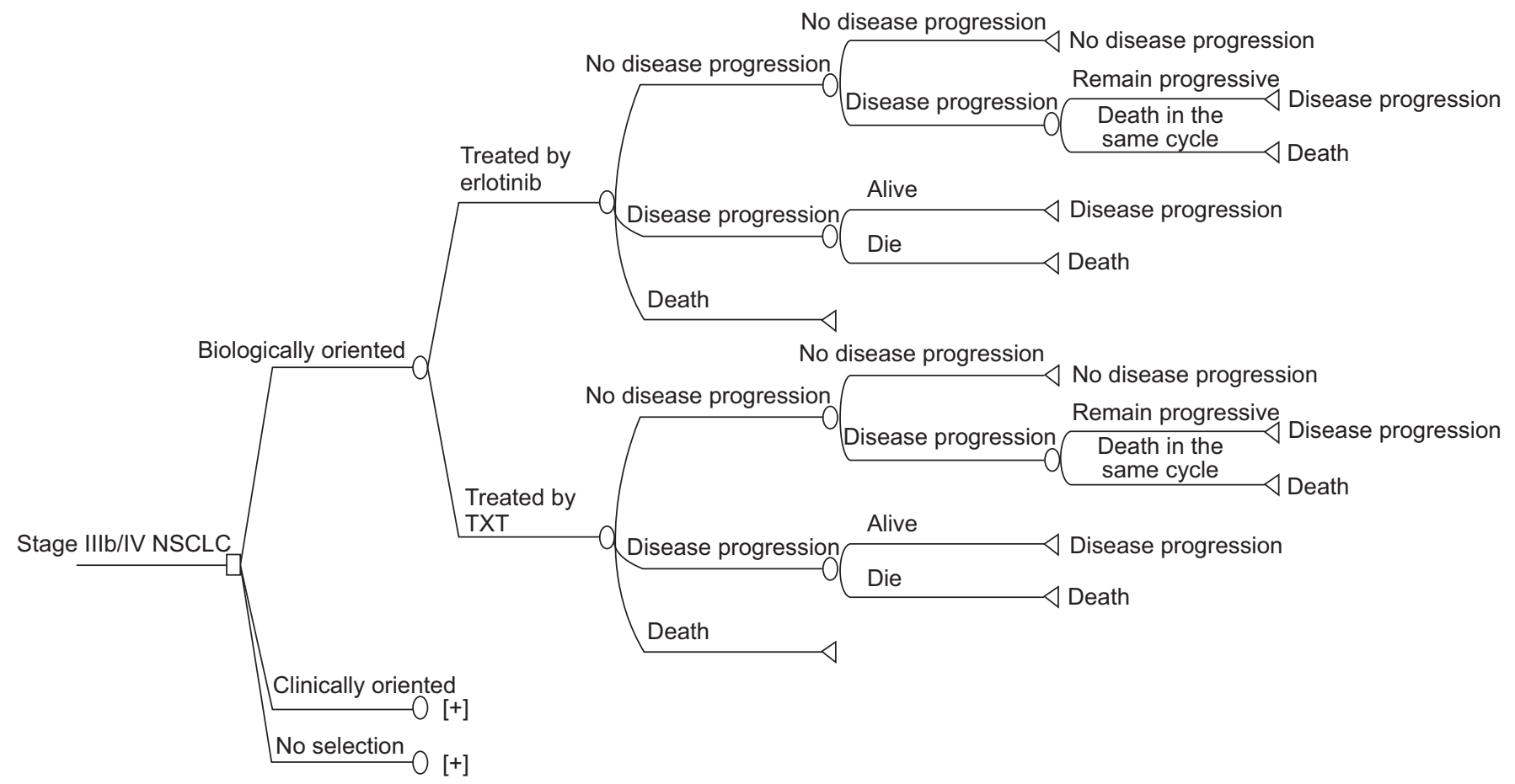

FIGURE 1. Markov model for second-line erlotinib initiation. NSCLC: nonsmall cell lung cancer; TXT: docetaxel. 
docetaxel has the same efficacy in a clinically selected population as in an EGFR wild-type population [17].

We used a Markov model, i.e. a multistate transitory model, in which patients make transitions through various health states, at different rates, and over extended periods [22]. The structure of the model was similar for the three strategies. The first node determined the nature of the treatment administered (erlotinib or docetaxel). The probability of receiving erlotinib was 1 in the noselection strategy (all patients received erlotinib), while it corresponded to the proportion, in the ERMETIC cohort, of neversmoking females with adenocarcinoma for the clinically guided strategy and to the proportion of EGFR-mutated patients for the biologically guided strategy. Then, whatever the treatment received, the course of NSCLC after treatment initiation was described using three exclusive health states: a progression-free state, a disease progression state and death (an absorbent state). The length of the Markov cycle was 1 month, meaning that patients made transitions among health states each month until death or until the end of a 30-month period (corresponding to the maximal follow-up period in the ERMETIC cohort). Patients who progressed were assumed to receive palliative care until death. In this model, using partition survival methods, the overall effectiveness of the strategies was derived by summing the mean time spent in the progression-free and disease progression health states, adjusted for quality of life, yielding quality-adjusted lifeyrs (QALY) and associated direct costs.

\section{Clinical inputs}

Clinical inputs were derived from individual patient data in the ERMETIC study [8] and the GFPC0506 study (table 1) [20]. ERMETIC [8] was a prospective observational multicentre cohort involving 522 consecutive patients with advanced NSCLC treated with second-line erlotinib between March 2007 and April 2008 at 16 French centres. In this study, outcomes (PFS and OS) and costs were prospectively recorded from erlotinib initiation until progression. The characteristics of the patients in this cohort are described in detail elsewhere [8]. Briefly, the median age was $63 \mathrm{yrs}, 32 \%$ of patients were female, $87 \%$ were Caucasian, $18 \%$ had never smoked, $65 \%$ had adenocarcinoma and $8.4 \%$ had EGFR mutations (table 1). The patients' EGFR statuses were systematically sought: testing was carried out by sequencing in each centre, under a national quality assurance programme [19]. The GFPC0506 study was a phase III, randomised, multicentre trial comparing the CERs of docetaxel and pemetrexed as second-line treatments for NSCLC. Outcomes and costs were prospectively assessed and 75 patients were enrolled in each arm between February 2006 and June 2008 by 27 French centres. The characteristics of the patients treated with docetaxel were the following: median age was $59 \mathrm{yrs}, 15 \%$ of patients were female, $93 \%$ of patients had a PFS of 0 or $1,9 \%$ had never smoked and $74 \%$ had adenocarcinoma. The EGFR status of these patients was unknown [20].

\section{Utilities}

Utilities were derived from community population-based studies of advanced NSCLC performed in the UK [23, 24], and used the standard gamble interview and a visual-analogue scale to assess quality of life (table 2).

\section{Costs}

Costs were estimated from the French healthcare payer's perspective during the period extending from second-line chemotherapy initiation until death. All resources consumed from second-line treatment initiation until disease progression were prospectively collected for each patient in both the ERMETIC cohort [8] and the GFPC0506 study [20]. Resources consumed were chemotherapy drugs, erlotinib, supportive treatments (including recombinant human erythropoietin, antiemetics, colony-stimulating factors, antibiotics, management of adverse effects, etc.), transfusion and hospitalisation for any reason. The specific unit costs are listed in table 2. Costs incurred after disease progression were derived from a representative

TABLE 1 Characteristic of the patients

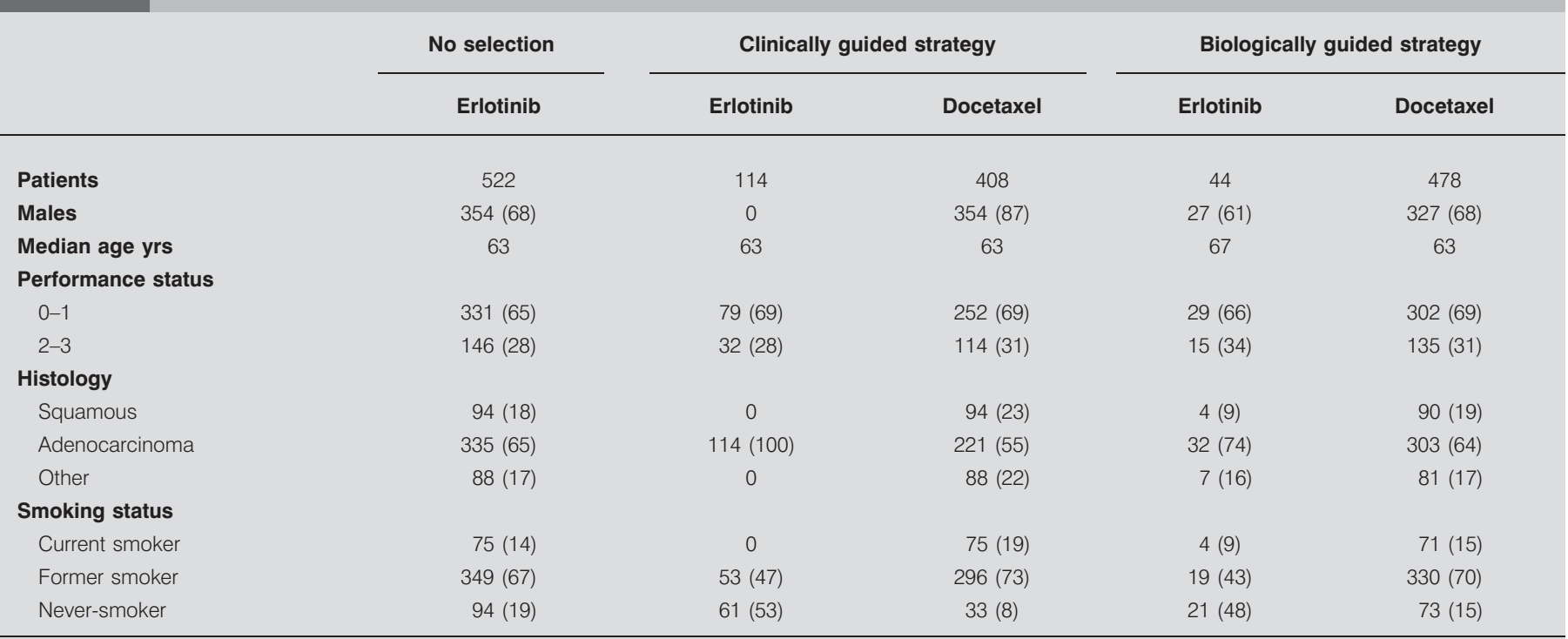




\begin{tabular}{|c|c|c|c|c|}
\hline & Base case & Low & High & [Ref.] \\
\hline \multicolumn{5}{|l|}{ Median OS months } \\
\hline No selection ${ }^{\#}$ & 5.6 & 4.6 & 7.0 & [8] \\
\hline \multicolumn{5}{|l|}{ Clinical selection } \\
\hline Positive & 9.4 & 5.5 & 12.7 & [8] \\
\hline Negative $^{+}$ & 8.0 & 5.1 & 10.4 & [8] \\
\hline \multicolumn{5}{|l|}{ EGFR-based selection } \\
\hline Positive ${ }^{\S}$ & 14.4 & 8.0 & 20.6 & [8] \\
\hline Negative ${ }^{f}$ & 8.0 & 5.1 & 10.4 & {$[8]$} \\
\hline \multicolumn{5}{|l|}{ Median PFS months } \\
\hline No selection ${ }^{\#}$ & 2.4 & 2.3 & 2.6 & [8] \\
\hline \multicolumn{5}{|l|}{ Clinical selection } \\
\hline Positive & 2.9 & 2.5 & 3.8 & [8] \\
\hline Negative $^{+}$ & 2.8 & 2.2 & 4.2 & [8] \\
\hline \multicolumn{5}{|l|}{ EGFR-based selection } \\
\hline Positivef & 8.4 & 3.0 & 15.3 & {$[8]$} \\
\hline Negative ${ }^{\# \#}$ & 2.8 & 2.2 & 4.2 & [20] \\
\hline Health state utilities & & & & {$[23,24]$} \\
\hline Stable disease on oral therapy & 0.670 & 0.27 & 0.80 & \\
\hline Stable disease on i.v. therapy & 0.653 & 0.26 & 0.78 & \\
\hline Progressive disease & 0.473 & 0.19 & 0.56 & \\
\hline Death & 0 & & & \\
\hline Prevalence of EGFR mutation & 0.08 & 0.01 & 0.15 & [8] \\
\hline \multicolumn{5}{|l|}{$\begin{array}{l}\text { Cost of medical services } \\
\text { and drugs } €\end{array}$} \\
\hline Erlotinib 30-day supply $150 \mathrm{mg}$ & 2174.7 & & & \\
\hline $\begin{array}{l}\text { Mean duration of erlotinib } \\
\text { treatment months }\end{array}$ & 2.5 & 0.1 & 26.0 & \\
\hline Docetaxel per mg & 10.7 & & & \\
\hline Mean number of docetaxel cycles & $3.7 \pm 1.9$ & & & \\
\hline $\begin{array}{l}\text { Cost of hospitalisation for } \\
\text { docetaxel administration }\end{array}$ & 368 & & & \\
\hline $\begin{array}{l}\text { Frequency of hospitalisation } \\
\text { for adverse events }\end{array}$ & $0.44 \pm 0.84$ & & & [25] \\
\hline G-CSF injection per cycle & 557.4 & 1627 & 3021 & \\
\hline Erythropoietin per cycle & 199.1 & 91 & 400 & \\
\hline $\begin{array}{l}\text { Palliative care after progression } \\
\text { per month }\end{array}$ & 2324 & & & \\
\hline EGFR test & 130 & & & \\
\hline
\end{tabular}

OS: overall survival; EGFR: epidermal growth factor receptor; PFS: progressionfree survival; G-CSF: granulocyte colony-stimulating factor. ${ }^{\#}: n=522$; ?: $n=114 ;^{+}: n=408 ;{ }^{s}: n=44 ;{ }^{f}: n=478 ;{ }^{\# \#}: n=75$.

French nationwide sample of 428 patients, using chart review to assess the mean direct monthly cost of the first 18 months of NSCLC patient management [25]. Specifically, the costs included out- and in-patient services, care provision at skilled nursing facilities, out- and in-patient drugs and other medications, nursing care organisation, home health visits and durable medical equipment. Assuming a yearly increment of 3.5\%, 1 month of palliative care cost $€ 2,324$ (according to the 2010 exchange rate; table 2). The cost of EGFR mutation screening was taken as the sum reimbursed to French hospitals. Discounting was applied at a rate of $3 \%$ for years 2 and 3 of the analysis.

\section{Cost-utility analysis}

Incremental CERs (ICERs) were calculated. These ratios correspond to the difference in costs divided by the difference in effectiveness based on the QALY between the two strategies. The cost-utility analysis conformed to the recommendations of the US Panel on Cost-Effectiveness in Health and Medicine [26].

\section{Statistical analysis}

PFS was defined as the time between second-line treatment initiation and the first subsequent event (progression or death from any cause). Patients who were alive and progression-free were censored at the date of their last follow-up visit. OS was defined as the time from second-line treatment initiation to death from any cause. Living patients were censored at the date of their last follow-up visit. For the ERMETIC study, the cut-off date was October 1, 2009, 18 months after enrolment of the last patient. The median follow-up period was 24 months. For the GFPC 0506 study, the cut-off date was August 31, 2009, 14 months after enrolment of the last patient. The median follow-up period was 28 months. PFS and OS were estimated with a monthly actuarial method to obtain the exact distribution of PFS and OS per Markov cycle, during a 30-month horizon time. This time horizon, which corresponded to the maximal follow-up period in the ERMETIC cohort, was chosen in order to avoid the need to extrapolate PFS and OS beyond the 30-month period.

\section{Assessing uncertainty}

The uncertainty in the model was evaluated by means of one-way sensitivity analysis. The estimate for a given model parameter was varied, while keeping the other parameters constant, within a range of likely values derived from confidence intervals or reasonable ranges in published sources. In addition, a multivariate probabilistic sensitivity analysis was implemented in a second-order Monte Carlo simulation in which the model inputs (PFS, OS, costs and transition probabilities) were drawn from individual data extracted from both the ERMETIC cohort and the GFPC0506 study. Specific distributions were assigned to utility data by using published means and standard deviations to derive a normal distribution. A simulation with 10,000 replications of the model was used to obtain the nonparametric $95 \%$ confidence intervals for the cost and effectiveness parameters, and to determine the proportion of replications in each quadrant of the cost-effectiveness plane. The multiway sensitivity analysis was presented in a radar screen format, where the $x$ axis shows the difference in effectiveness and the $y$-axis shows the difference in costs between two strategies. Dots represent the 10,000 replications. SAS software version 9 (SAS Institute Inc., Cary, NC, USA) and Data TreeAge Pro Health Care (TreeAge Software, Inc.; Data, Williamstown, MA, USA) were used for statistical analyses and modelling, respectively.

\section{RESULTS}

The results of the model are shown in table 3. The median PFS and OS in the entire ERMETIC cohort ( $n=522$ patients) were 2.4 and 5.6 months, respectively. In the subgroup of nonsmoking females with adenocarcinoma ( $n=114$ patients), the median PFS and OS values were 2.9 and 9.4 months, respectively. The median PFS and OS for the 44 EGFR-mutated patients were 8.4 and 14.4 months, respectively. In the GFPC0506 study, the median PFS and OS for the 75 patients treated with docetaxel 
TABLE 3 Mean cost and effectiveness per patient by strategy

\begin{tabular}{lccc} 
Strategy & No selection & Clinically guided & Biological guided \\
\hline $\begin{array}{l}\text { QALY } \\
\begin{array}{l}\text { Incremental QALY as compared with } \\
\text { the no-selection strategy QALY }\end{array}\end{array}$ & $0.478 \pm 0.098$ & $0.558 \pm 0.082$ & $0.559 \pm 0.092$ \\
$\begin{array}{l}\text { Cost } € \\
\text { Incremental cost as compared with the }\end{array}$ & 0.080 & 0.081 \\
$\quad$ no-selection strategy $€$ & $21025 \pm 12175$ & $16005 \pm 6758$ & $15210 \pm 6860$ \\
CER $€ \cdot$ QALY $^{-1}$ & & -5020 & -5815 \\
\hline
\end{tabular}

Data are presented as mean \pm SD, unless otherwise stated. QALY: quality-adjusted life-yrs; CER: cost-effectiveness ratio.

were 2.8 and 8.0 months, respectively. The model yielded mean life expectancies of 9.9, 11.6 and 11.7 months, respectively, for the strategies with no selection, clinical selection and biological selection. QALY estimates were $0.478,0.558$ and 0.559 QALY, respectively. The no-selection strategy was therefore the least effective, while the clinically and biologically guided strategies had equivalent efficacy. The incremental efficacy of the clinically and the biologically guided strategies were, respectively, 0.080 and 0.081 QALY, as compared with the no-selection strategy. Cost estimates were $€ 21,025, € 16,005$ and $€ 15,210$, respectively, for the strategies with no selection and clinical and biological selection (table 3). The clinically and biologically guided strategies were less expensive, being $€ 5,020$ and $€ 5,815$, respectively, as compared with the no-selection strategy (table 3). The no-selection strategy was both the least effective and the most expensive. The biologically and clinically guided strategies were dominant, but the biological strategy was slightly less expensive than the clinical strategy.
The results of the one-way sensitivity analysis are shown in table 4 . Whatever the parameter that was varied, the noselection strategy was systematically less effective and more expensive than the other two strategies. Assuming a low prevalence of EGFR mutation (i.e. 1\%), the clinically guided strategy was more effective but more expensive than the biologically guided strategy, with an ICER of $€ 96,354$ per QALY. Conversely, the biologically guided strategy was more effective but more expensive than the clinically guided strategy when the EGFR mutation prevalence was $30 \%$, with an ICER of $€ 40,147$ per QALY. Variations of cost parameters never challenged the conclusions drawn from the base case.

Figures 2 and 3 shows the results of multivariate probabilistic sensitivity analyses. The no-selection strategy was dominated by the clinical and biological strategies in $61 \%$ and $64 \%$ of cases, respectively. Comparison of the latter two strategies showed an equal distribution of replications among the four

\section{TABLE 4 Sensitivity analysis}

\begin{tabular}{|c|c|c|c|}
\hline Base case & 43985 & 28682 & 27209 \\
\hline Non-smokers with adenocarcinoma & $43985^{\#}$ & 26682 & $27209^{\#}$ \\
\hline Non-smoker females & $43985^{\#}$ & 30671 & $27209^{\#}$ \\
\hline 1 & $43985^{\#}$ & $28682^{\#}$ & 25927 \\
\hline 30 & $43985^{\#}$ & $28682^{\#}$ & 29802 \\
\hline \multicolumn{4}{|l|}{ Biological testing cost $€$} \\
\hline 91 & $43985^{\#}$ & $28682^{\#}$ & 27071 \\
\hline 400 & $43985^{\#}$ & $28682^{\#}$ & 27504 \\
\hline-30 & 38311 & 27096 & 26193 \\
\hline+30 & 49661 & 30129 & 28060 \\
\hline
\end{tabular}

Data are presented as cost in Euros $(€)$. EGFR: epidermal growth factor receptor. ${ }^{*}$ : same estimates as for the base case. 

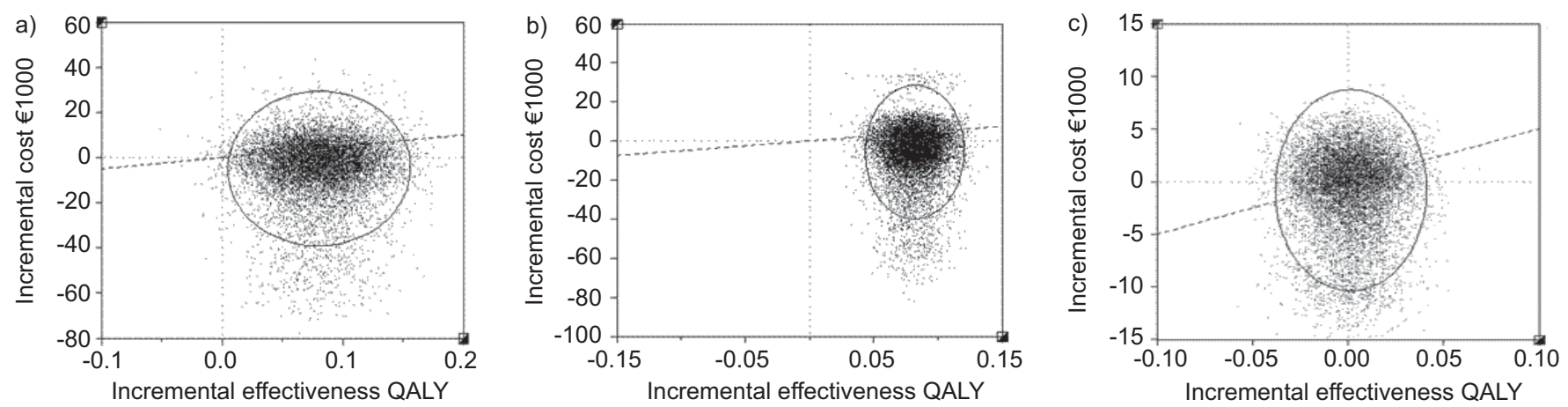

FIGURE 2. Multivariate probabilistic sensitivity analysis (results of a 10,000-replication simulation). Each figure represents a cost-effectiveness plane of the comparison of two strategies. a) Clinically guided strategy versus no-selection strategy. b) Biologically guided strategy versus no-selection strategy. c) Clinically guided strategy versus biologically guided strategy. QALY: quality-adjusted life-yrs.

quadrants of the cost-effectiveness plan, demonstrating the equivalent cost-effectiveness of the two strategies.

\section{DISCUSSION}

This cost-effectiveness study shows that three strategies of second-line erlotinib initiation for NSCLC, namely no patient selection, and patient selection on clinical or biological grounds, had respective cost-effectiveness ratios of $€ 43,985, € 28,683$ and $€ 27,209$ per QALY. The no-selection strategy was inferior to the other two strategies not only in the base case scenario, but also in all the scenarios tested by sensitivity analysis. Multivariate probabilistic sensitivity analysis showed the equivalence of the clinical and biological strategies in terms of the CER.

Few economic studies of second-line treatments for advanced NSCLC have been published [21, 27, 28], and most are based on models using clinical trial data. The ICER of second-line erlotinib versus placebo in patients with previously treated advancedstage NSCLC has recently been published [29]. Resource utilisation was determined from individual patient data in the BR21 trial database. The ICER was \$94,638 (in 2007 Canadian dollars; 95\% CI $\$ 52,359-429,148)$ per life-yr gained. The main drivers of cost-effectiveness included the magnitude of the

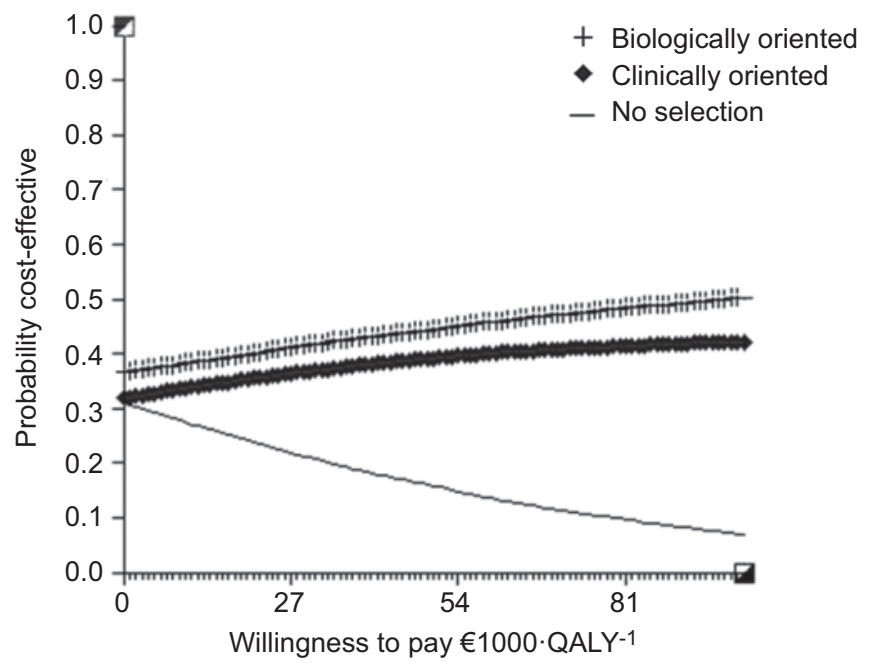

FIGURE 3. Acceptability curve showing the probability for each strategy of being cost-effective. QALY: quality-adjusted life-yrs. survival benefit and the cost of erlotinib. Subgroup analyses showed that the ICER was better in never-smokers, but not in females; likewise, a high EGFR gene copy number, contrary to EGFR mutations, was associated with a favourable ICER. The authors concluded that the patient population most likely to benefit from this drug needed to be better defined. In this study, efficacy was measured in terms of years of life gained, with no weighting for quality of life. However, the latest guidelines recommend that quality of life be taken into account when considering second-line treatment for NSCLC [30]. Regarding the burden of NSCLC in terms of health-related quality of life, little information is available on the preferences of patients or society with respect to disease states. We used data from NAFEES et al. [24], who adapted existing health-state descriptions in metastatic breast cancer to evaluate the utilities of patients receiving second-line treatment for NSCLC. Each health state describes the symptom burden of a disease and its functional impact. More recently, LEWIS et al. [23] used the same method to establish health utilities for erlotinib therapy, based on data for 154 members of the UK general population, using the EuroQol EQ-5D instrument (www.euroqol.org/). We used the results of both studies to test the robustness of our model with varying utility values.

There are few published cost-effectiveness studies directly comparing erlotinib with other agents (docetaxel and pemetrexed). In a model-based analysis [31], the economic value of docetaxel, pemetrexed and erlotinib was compared in a cohort of no clinically or EGFR-mutated selected patients with refractory advanced-stage NSCLC. The authors developed a decision analysis model to evaluate, from the US payer's perspective, the incremental costs and QALY of these three drugs, based on efficacy and adverse event rates observed in published clinical trials. The authors used the work of NAFEES et al. [24] for the utilities and publicly available cost sources. They found that treatment with erlotinib, docetaxel and pemetrexed yielded 0.42 , 0.41 and 0.41 QALY, respectively, compared with $0.478,0.558$ and 0.559 QALY, respectively, in our no-selection, clinically guided selection and biologically guided selection strategies. Total costs were US\$37,000, 39,100 and 43,800 for erlotinib, docetaxel and pemetrexed, respectively, compared with $€ 21,025$, 16,005 and 15,210, respectively, in our study. A more recent costutility analysis compared erlotinib with docetaxel for second-line management of advanced NSCLC in the UK National Health 
Service [23]. The authors used a health-state transition model based on the two pivotal phase III studies of erlotinib versus best supportive care and docetaxel versus best supportive care, to estimate direct costs, QALY and the subsequent net monetary benefit. Erlotinib was associated with a reduction in total costs $(£ 13,730$ versus $£ 13,956)$ and a gain in QALY. The comparison of our results with those of these studies confirms the importance of patient selection (on clinical or biological grounds) for costeffective erlotinib therapy.

An advantage of our study was the prospective cost collection of data and, at least in the ERMETIC study, a cohort of patients representative of those receiving second-line treatment in the routine clinical setting. However, our study has certain limitations. First, costs were identified prospectively only during the active treatment periods. Management costs after the end of active treatments were derived from a 2004 national database. Some patients may have received third-line chemotherapy, but the cost of these chemotherapies would be the same for the three strategies and would not impact on the final results. Secondly, our analysis was limited to direct lung cancer-related medical costs: indirect costs, such as lost productivity and caregiver salaries, were not included. Thirdly, the way in which we expressed utilities reflects the value from the point of view of society rather than that of the patients concerned. As this study is based on an indirect comparison, we have no information on the clinical efficacy, safety and resource utilisation for the interventions in the same population. We also assumed the same OS benefit of docetaxel in a general population and in nonmutated and clinically selected populations, although the use of sensitivity analyses overcomes these limitations. The conclusions based on the base-case scenario were not modified when we varied the different model parameters; however, uncertainty concerning costs and effectiveness may be still present. Ultimately, head-to-head comparative trials will be needed to determine whether there are significant differences between the treatment strategies in terms of OS or PFS.

In conclusion, the cost-effectiveness ratios of the three strategies tested here for second-line erlotinib initiation in patients with advanced-stage NSCLC are within the limits considered acceptable for society, although patient selection based on clinical grounds or EFGR mutation status appears to improve cost-effectiveness.

\section{SUPPORT STATEMENT}

ERMETIC was funded by the French Ministry of Health, through the National Institute for Cancer (INCa; J. Cadranel, C. Chouaid and J-P. Pignon). None of the funding agencies were involved in the study design or conduct, data management or analysis, manuscript preparation or review, or the decision to submit the manuscript for publication.

\section{STATEMENT OF INTEREST}

Statements of interest for I. Borget, J. Cadranel, J-P. Pignon, E. Quoix, B. Coudert, V. Westeel, E. Dansin, F. Morin and C. Chouaid can be found at www.erj.ersjournals.com/site/misc/statements.xhtml

\section{ACKNOWLEDGEMENTS}

The ERMETIC Collaborative Group were: V. Gounant, A. Lavole, B. Milleron, M. Wislez., M. Antoine and V. Poulot (AP-HP Hôpital Tenon, Paris, France); P. Cervera, N. Hoyeau-Idrissi, M. Baud and M. Febvre (AP-HP Hôpital St-Antoine, Paris); C. Danel, E. FabreGuillevin, J. Médioni, M. Riquet and H. Blons (Hôpital Européen
Georges Pompidou, Paris); F. Coulet (Paris Pitié Salpétrière, Paris); B. Besse, J.M. Bidart, J. Bosq, P. Fouret, L. Lacroix, J.C. Soria, G. Danton, A. Maugen, E. Rolland, P. Saulnier and S. Michiels (Institut Gustave Roussy, Villejuif, France); J. Chasles, F. Galateau-Salle, R. Gervais, A. Hardouin, M.L. Kottler, S. Lecot-Cotigny, J. Madelaine, H. Mittre, A. Rivière., G. Zalcman and N. Richard (CHU-CLCC, Caen, France); C. Brambilla, E. Brambilla, S. Dufort, M.C. Favrot, S. Lantuejoul, D. Moro-Sibilot and F. de Praipont (CHU, Grenoble, France); F. Clément, P.E. Falcoz, P. Jacoulet, M. Gainet, C. Mougin, E. Ranfaing, V. Westeel and J.L. Pretet (CHU, Besançon, France); M. Carrère, A. Chapelier, P. de Cremoux, C. Daniel, M. Laë, C. Luco, X. Sastre-Garau and A. Degeorges (Institut Curie, Paris); M.P. Chenard, M.P. Gaub, B. Mennecier, A. Neuville, P. Oudet, E. Quoix, A.M. Ruppert and M. Beau-Faller (Hôpitaux Universitalres de Strasbourg, Strasbourg, France); B. Chetaille, A. Goncalves, I. Madroszyk, V. Rémy, P. Viens, L. Xerri and S. Olschwang (CLCC Padi Calmette, Marseille, France); M.C. Copin, E. Dansin, J.J. Lafitte, A. Lansiaux, Y.M. Robin, A. Scherpereel, M.P. Buisine (CLCC-CHU, Lille, France); L. Arnould, A. Bernard, B. Coudert, A. Fanton, P. Foucher, F. Piard and S. Lizard (CLCC-CHU, Dijon, France); A. Chapelier, H. Doubre, S. Friard, E. Longchampt, C. Andrieu, R. Lidereau and I. Bieche (Suresnes Hôpital Foch and Saint-Cloud Centre René Huguenin, Paris); H. Chapuis, E. Coste, M. Taulelle, V. Vidal and J.C. Boyer (CHU, Nîmes, France); J. Hureaux, Y. Le Guen, Y. Malthiery, P. Reynier, M.C. Rousselet-Chapeau, F. Savagner, T. Urban and D. Prunier-Mirebeau (CHU, Angers, France); and M. Mounawar, P. Hainaut (IARC, Lyon, France).

\section{REFERENCES}

1 Warren JL, Yabroff KR, Meekins A, et al. Evaluation of trends in the cost of initial cancer treatment. J Natl Cancer Inst 2008; 100: 888-897.

2 Chouaid C, Atsou K, Hejblum G, et al. Economics of treatments for non-small cell lung cancer. Pharmacoeconomics 2009; 27: 113-125.

3 Tassinari D, Scarpi E, Sartori S, et al. Second-line treatments in non-small cell lung cancer. A systematic review of literature and metaanalysis of randomized clinical trials. Chest 2009; 135: 1596-1609.

4 Hanna N, Shepherd FA, Fossella FV, et al. Randomized phase III trial of pemetrexed versus docetaxel in patients with non-small-cell lung cancer previously treated with chemotherapy. J Clin Oncol 2004; 22: 1589-1597.

5 Shepherd FA, Dancey J, Ramlau R, et al. Prospective randomized trial of docetaxel versus best supportive care in patients with nonsmall-cell lung cancer previously treated with platinum-based chemotherapy. J Clin Oncol 2000; 18: 2095-2103.

6 Shepherd FA, Rodrigues Pereira J, Ciuleanu T, et al. Erlotinib in previously treated non-small-cell lung cancer. N Engl J Med 2005; 353: 123-132.

7 Reck M, van Zandwijk N, Gridelli C, et al. Erlotinib in advanced non-small cell lung cancer: efficacy and safety findings of the global phase IV Tarceva Lung Cancer Survival Treatment study. J Thorac Oncol 2010; 5: 1616-1622.

8 Cadranel J, Coudert B, Mauguen A, et al. Clinical and biological predictors of progression-free survival (PFS) and overall survival (OS) in patients (pts) with advanced non-small-cell lung cancer (NSCLC) treated by erlotinib in the ERMETIC cohort. Eur Respir J 2010; Suppl. 54, 1942.

9 Faehling M, Eckert R, Kuom S, et al. Benefit of erlotinib in patients with non-small-cell lung cancer is related to smoking status, gender, skin rash and radiological response but not to histology and treatment line. Oncology 2010; 78: 249-258.

10 Cappuzzo F, Hirsch FR, Rossi E, et al. Epidermal growth factor receptor gene and protein and gefitinib sensitivity in non-smallcell lung cancer. J Natl Cancer Inst 2005; 97: 643-655.

11 Clark GM, Zborowski DM, Culbertson JL, et al. Clinical utility of epidermal growth factor receptor expression for selecting patients 
with advanced non-small cell lung cancer for treatment with erlotinib. J Thorac Oncol 2006; 1: 837-846.

12 Han SW, Kim TY, Hwang PG, et al. Predictive and prognostic impact of epidermal growth factor receptor mutation in nonsmall-cell lung cancer patients treated with gefitinib. J Clin Oncol 2005; 23: 2493-2501.

13 Lynch TJ, Bell DW, Sordella R, et al. Activating mutations in the epidermal growth factor receptor underlying responsiveness of non-small-cell lung cancer to gefitinib. $N$ Engl J Med 2004; 350: 2129-2139.

14 Tsao MS, Sakurada A, Cutz JC, et al. Erlotinib in lung cancer molecular and clinical predictors of outcome. N Engl J Med 2005; 353: 133-144.

15 Rosell R, Moran T, Queralt C, et al. Screening for epidermal growth factor receptor mutations in lung cancer. N Engl J Med 2009; 361: 958-967.

16 Mok TS, Wu YL, Thongprasert S, et al. Gefitinib or carboplatinpaclitaxel in pulmonary adenocarcinoma. N Engl J Med 2009; 361: 947-957.

17 Kim ES, Hirsh V, Mok T, et al. Gefitinib versus docetaxel in previously treated non-small-cell lung cancer (INTEREST): a randomised phase III trial. Lancet 2008; 372: 1809-1818.

18 Cadranel J, Zalcman G, Sequist L. Genetic profiling and epidermal growth factor receptor-directed therapy in nonsmall cell lung cancer. Eur Respir J 2011; 37: 183-193.

19 Beau-Faller M, Degeorges A, Roland E. Cross-validation study of EGFR and K-Ras mutation detection in 74 blinded non small cell lung carcinoma samples: 5550 exons sequenced by 15 molecular French laboratories (ERMETIC project - part 1). J Thor Oncol 2011; 6: 1006-1015.

20 Vergnenegre A, Corre R, Berard $\mathrm{H}$, et al. Cost-effectiveness of second-line chemotherapy for non-small cell lung cancer: an economic, randomized, prospective, multicenter phase III trial comparing docetaxel and pemetrexed: the GFPC 05-06 study. J Thorac Oncol 2011; 6: 161-168.
21 Carlson JJ, Garrison LP, Ramsey SD, et al. The potential clinical and economic outcomes of pharmacogenomic approaches to EGFR-tyrosine kinase inhibitor therapy in non-small-cell lung cancer. Value Health 2009; 12: 20-27.

22 Doubilet $\mathrm{P}$, Begg CB, Weinstein $\mathrm{MC}$, et al. Probabilistic sensitivity analysis using Monte Carlo simulation. A practical approach. Med Decis Making 1985; 5: 157-177.

23 Lewis G, Peake M, Aultman R, et al. Cost-effectiveness of erlotinib versus docetaxel for second-line treatment of advanced non-smallcell lung cancer in the United Kingdom. J Int Med Res 2010; 38: 9-21.

24 Nafees B, Stafford M, Gavriel S, et al. Health state utilities for non small cell lung cancer. Health Qual Life Outcomes 2008; 6: 84.

25 Chouaid C, Molinier L, Combescure C, et al. Economics of the clinical management of lung cancer in France: an analysis using a Markov model. Br J Cancer 2004; 90: 397-402.

26 Cost-Effectiveness in Health and Medicine. In: Gold MR, Siegel JE, Russell LB, Weinstein MC, eds. New York, Oxford University Press, 1996.

27 Holmes J, Dunlop D, Hemmett L, et al. A cost-effectiveness analysis of docetaxel in the second-line treatment of non-small cell lung cancer. Pharmacoeconomics 2004; 22: 581-589.

28 Leighl NB, Shepherd FA, Kwong R, et al. Economic analysis of the TAX 317 trial: docetaxel versus best supportive care as second-line therapy of advanced non-small-cell lung cancer. J Clin Oncol 2002; 20: 1344-1352.

29 Bradbury PA, Tu D, Seymour L, et al. Economic analysis: randomized placebo-controlled clinical trial of erlotinib in advanced non-small cell lung cancer. J Natl Cancer Inst 2010; 102: 298-306.

30 Trippoli S, Vaiani M, Lucioni C, et al. Quality of life and utility in patients with non-small cell lung cancer. Quality-of-life Study Group of the Master 2 Project in Pharmacoeconomics. Pharmacoeconomics 2001; 19: 855-863.

31 Carlson JJ, Reyes C, Oestreicher N, et al. Comparative clinical and economic outcomes of treatments for refractory non-small cell lung cancer (NSCLC). Lung Cancer 2008; 61: 405-415. 